\title{
Fenômeno e objeto na Fenomenologia de Merleau-Ponty
}

José Luís Neves - Universidade Federal de São Carlos

Haveria na Fenomenologia da percepção uma doutrina unívoca acerca do objeto intencional, o "percebido enquanto tal" visado pela percepção? O que ocorre com esse conceito, forjado em contexto epistemológico e transcendental, ao ser acomodado numa autointitulada "filosofia da existência"? Quando Husserl formulava esse conceito após a dita virada idealista, ele o fazia respeitando três condições indispensáveis à sua coerência teórica: primeiro, a efetuação da redução fenomenológica, com a qual se afasta a tese de existência operante na atitude natural; segundo, a dissolução do caráter de em-si do objeto visado, em benefício de seus múltiplos modos de doação, de cuja consideração a fenomenologia passa exclusivamente a se ocupar; terceiro, o consequente entendimento do a priori da correlação em sentido reduzido, isto é, como relação necessária de dependência não entre sujeito e objeto puro e simples, tomados como seres reais da natureza, mas entre consciência e objeto "em seu modo 
de doação". Entre essas três condições elas mesmas, a relação é a cada vez de premissa a consequência: a redução implica a dissolução do em-si da coisa, e é esse gesto que acarreta a relatividade do objeto à consciência, uma vez que, efetuada a epoché, o objeto não pode mais ser compreendido senão como correlato de múltiplas prestações intencionais. Isso equivale a dizer que o a priori da correlação, tema constante e fio condutor das descrições fenomenológicas, só ganha direito de cidadania após a supressão do em-si, o ente ele mesmo sem perfis, tal como interpretado pela atitude natural. A doutrina do objeto intencional presente na fenomenologia madura é resultado direto dessas teses: graças à supressão do em-si, o objeto visado através dos atos intencionais é doravante apenas o mesmo de uma diversidade de aparições (Erscheinungen) que o apresentam à consciência, o "X idêntico e vazio" de uma multiplicidade noemática, no jargão de Ideias I. Se tudo de que se tem experiência é por princípio uma relatividade, aquilo em que se transforma, após a redução, o antigo irrelativo - a coisa ela mesma que os atos da consciência procurariam atingir -, só poderá ser a presunção de mesmidade dessas relatividades, aquilo de comum que todos os modos de doação apresentam, sem jamais apresentá-lo diretamente e sem a mediação de aparições.

O importante aqui não é apenas notar que o objeto intencional marca o idêntico de uma série de aparições, mas sobretudo que, sendo idêntico, ele não deixa por isso de ser vazio: ele não indica uma mesma "realidade", capaz de ser visada nela mesma sem o ser através de um modo "subjetivo" de doação, num "como" preciso de ser dado. Supor o contrário, isto é, postular kantianamente um em-si incognoscível, atrás ou aquém dos fenômenos dos quais é presumidamente fonte, isso tornaria a relação en- 
tre a coisa e sua manifestação inevitavelmente exterior, pondo a perder a capacidade de as aparições ostenderem o aparecente com a evidência da doação-em-pessoa. Para evitar a consequência, é preciso compreender a "mesmidade" do objeto intencional sem o idioma renitente do realismo empírico: ele será a unidade presuntiva de uma série de aparições convergentes, o "mesmo" ostendido na concordância de apresentações, mas nenhuma realidade "além" ou "atrás" delas - e nesse sentido, "vazio". Assim, se o objeto é "transcendente" em relação à série de aparições concordantes através das quais se doa, por que é aquilo que através delas aparece, essa transcendência não deve ser compreendida em sentido "real", não havendo oposição natural entre objeto e série aparições, apenas uma "transcendência na imanência" - no caso em tela, a transcendência do objeto idêntico em relação à multiplicidade fenomênica. É apenas graças a essa decodificação do objeto intencional como "transcendência na imanência" que ele poderá ser a priori correlativo às prestações intencionais da subjetividade:

todo ente que é válido para mim e para todo sujeito imaginável, enquanto efetivamente ente, é por isso mesmo correlativo, e ele é, por uma necessidade de essência, o index do sistema de sua diversidade. Cada um indica uma universalidade ideal de seus modos de doação em uma experiência real ou possível, e cada um desses modos de doação é aparição desse único ente (Husserl, 1976, p. 169; trad. p. 189).

A partir daqui, o comentário já poderá mostrar que, com a supressão do em-si e a consequente interpretação do objeto intencional como $\mathrm{X}$ idêntico de uma multiplicidade noemática - 
e nenhuma realidade subsistente por si -, a subjetividade fenomenológica não tem mais "nenhum exterior a si" e se converte, então, na mônada à qual a totalidade de objetos passa a pertencer a título de parte intencional, isto é, como transcendência na imanência (Moura, 1989, p. 181). Mas, se é assim, não se vê exatamente como essa doutrina fenomenológica do objeto intencional, entendido como X idêntico de uma multiplicidade de aparições, seria apartável do idealismo transcendental em cujo interior ela é gestada, e isso tanto mais quanto ela parece ter sido talhada sob medida para neutralizar a ideia de uma exterioridade independente da consciência, alçando desse modo esta última à qualidade de mônada. Mas então voltemos ao ponto de partida. Uma doutrina do objeto intencional - em MerleauPonty?

\section{II}

Pode parecer estranho. Afinal, a Fenomenologia da percepção não cessa de recriminar no idealismo transcendental a "redução" que transforma o mundo em "pensamento ou consciência de mundo", com o que este "se torna imanente à consciência" e consequentemente se suprime a "aseidade das coisas" (MerleauPonty, 2001a, p. x). Em verdade, Merleau-Ponty não se limita a rejeitar epidermicamente essa funesta consequência - ele procura extirpar suas raízes metodológicas, e isso desde o momento em que reinterpreta a premissa maior que levara Husserl à doutrina idealista do objeto intencional. Assim, a redução fenomenológica com que Husserl suspendia a tese de existência se transforma, na Fenomenologia da percepção, na constatação da "redução incompleta": toda reflexão, dirá Merleau-Ponty, pressupõe um fundo irrefletido que ela não absorve, a saber, no mínimo 
o fluxo temporal da consciência no qual o ato de reflexão ocorre e com o qual ela procura sem sucesso coincidir (Ibid., p. viii-ix). Deve-se então reconhecer ao menos esta existência irredutível, a da "vida irrefletida" da consciência pela qual sempre-já "estamos no mundo" antes de refleti-lo. Donde a conclusão inversa à de Husserl: "longe de ser, como se acreditou, a fórmula de uma filosofia idealista, a redução fenomenológica é a fórmula de uma filosofia existencial" (Ibid., p. ix).

A revisão merleau-pontiana do a priori da correlação será uma decorrência dessa incompletude da redução. Em Husserl, era a epoché radical que, purificando a consciência de suas implicações mundanas (o mundo de objetos e ela mesma como consciência empírica), tornava-a constituinte universal do polo de objetividades. Se doravante a redução for sempre incompleta, a consciência, por não se desimplicar do mundo, tampouco se torna polo puramente constituinte, transparente a si mesmo, de modo que a intencionalidade de ato, associada por MerleauPonty à ordem da intelecção, mostra-se secundária em relação a uma intencionalidade mais primitiva, a "intencionalidade operante" que, antes de qualquer atividade da consciência, "forma a unidade natural e antepredicativa do mundo e de nossa vida" (Ibid., p. xiii). É por isso que, nessa reinterpretação do a priori da correlação, a unidade do mundo não é mais "constituída", e sim, "antes de ser posta pelo conhecimento e em um ato expresso de identificação, é vivida como já feita ou já dada" (Ibid., p. xii). $\mathrm{Na}$ verdade, entre a versão intelectualista do priori da correlação - na qual o mundo é "constituído" como idealidade - e essa sua nova versão existencial - na qual o mundo é "previamente dado" -, a distância é tão-somente aquela que separa intencionalidade de ato e intencionalidade operante, Sinngebung ativa 
da consciência e as sínteses passivas da temporalidade. Isso significa que, com o reconhecimento de um mundo "já dado", não se está flertando com o realismo empírico: o objeto e o mundo ainda carecem de uma subjetividade para a qual se dão, e o que se afastou aqui foi somente a modalidade tética da consciência, sem por isso afastar toda figura da consciência. É dizer que o $a$ priori da correlação, segundo o qual só há objeto para alguém, não foi abandonado, mas reinterpretado dentro do quadro de uma fenomenologia da passividade - observação aparentemente banal, porém decisiva para se entender o destino da doutrina do objeto intencional em mãos merleau-pontianas.

Bastam a tese da redução incompleta e a consequente reinterpretação do a priori da correlação, agora comandado pela intencionalidade operante - que "encontra" o mundo em vez de "constituí-lo" -, para se devolver às coisas a "aseidade" que o intelectualismo lhes havia roubado? Tudo se resume a bem compreender o que ocorreu, nessa nova figura do a priori correlacional, com a "dissolução do em-si" que patrocinava a doutrina do objeto intencional na fenomenologia clássica. Pois, se o mundo não deve mais ser dragado para o interior da subjetividade monádica, o impulso mais óbvio será dizer que se recuperou a ideia de uma "realidade exterior", irredutível às prestações subjetivas e independente destas, para a alegria do realismo ingênuo da atitude natural. É a esse impulso interpretativo que Gurwitsch visivelmente cede ao acusar Merleau-Ponty de ter restaurado, com uma suposta distinção entre a coisa dada em "evidência perceptiva", por um lado, e sua "série de aparências ou aspectos concordantes", por outro, a oposição pré-fenomenológica entre objeto e manifestação (Gurwitsch, 1957, p. 239). Assim, onde Merleau-Ponty sustenta que, ao percebermos algo, "não come- 
çamos por conhecer os aspectos perceptivos da coisa, ela não é mediatizada por nossos sentidos, nossas sensações, nossas perspectivas, nós vamos diretamente a ela" (Merleau-Ponty, 2001a, p. 374), o intérprete verá nesse texto a confissão de que se supõe ali a existência de um em-si diferente e irredutível à série de perfilhamentos noemáticos. Donde a oposição real, inaceitável para uma fenomenologia coerente, entre uma "série concordante e indefinida de visões sobre o objeto" e o "objeto em sua plenitude" (Ibid., p. 84; apud Gurwitsch, 1957, p. 239). Essa oposição entre objeto e manifestação, compreendendo o objeto como uma transcendência real em relação às aparições, permitiria afastar uma doutrina eminentemente idealista da coisa percebida, como aquela que a apresenta como o X idêntico e vazio de uma multiplicidade noemática; mas isso ao custo óbvio de compreendê-la pré-fenomenologicamente como uma realidade efetiva por detrás das aparições, que se tornam desde então meramente psicológicas, incapazes portanto de apresentar em pessoa aquilo que aparece.

Resta que essa interpretação do objeto intencional como realidade existente "para além" da série concordante de aparições esbarra tanto na letra quanto no espírito da Fenomenologia da percepção. Merleau-Ponty é nesse ponto tão fiel a Husserl quanto Gurwitsch, seguindo à risca a recomendação do mestre de se rejeitar o "em-si" como realidade oposta à série de seu perfilhamento. Gurwitsch acreditava que era por não ter realizado uma "investigação aprofundada" do aspecto noemático da correlação que Merleau-Ponty teria sido levado a opor sistema de aparições e objeto percebido, sem atinar com o fato de que,

em uma orientação estritamente fenomenológica, não há qualquer motivo para distinguir a coisa ela mesma 
de um grupo sistematicamente encadeado de noemas perceptivos que reenviam todos intrinsecamente uns aos outros, e que, em virtude desses reenvios mútuos, se qualificam uns aos outros (Gurwitsch, 1957, p. 241).

Dá-se aqui o raro caso em que crítico e criticado concordam perfeitamente, já que o conceito merleau-pontiano de expressão, na Fenomenologia, é exatamente o comentário desse tipo de reenvio mútuo entre fenômenos reivindicado por Gurwitsch. Mas então vejamos, inicialmente, como entender esse reenvio expressivo entre fenômenos - nos termos de Gurwitsch, entre "noemas perceptivos" - que faz crítico e criticado convergirem numa mesma tese explícita.

\section{III}

Sabe-se que uma das principais tarefas da Fenomenologia é desvelar uma presença autóctone do sentido no mundo sensível, de maneira a desbaratar a dualidade de signo e significação da qual empirismo e intelectualismo permaneciam ambos tributários. Vem dessa batalha o tema da expressividade da coisa sensível, entendendo por esse nome o reenvio intencional que se desdobra entre as qualidades sensíveis e que por si só produz, sem carecer de um ato animador da consciência, a ostensão da coisa percebida. Existe, dirá a Fenomenologia, uma "simbólica" da coisa que "liga cada qualidade sensível às outras" e que funciona como uma linguagem na qual "a significação seria secretada pela própria estrutura dos signos" (Merleau-Ponty, 2001, p. 369). Merleau-Ponty será bastante pródigo nos exemplos desses a priori materiais a ligar internamente as qualidades sensíveis: é a priori necessário que "um objeto muito quente se averme- 
lhe" (Ibid., p. 369), que uma determinada cor "anuncie" certa textura e, esta, uma sonoridade (Ibid., p. 41), etc. Ora, como é através dessa remissão recíproca entre as qualidades intra e intersensoriais que se produz a ostensão da coisa percebida, o sentido imanente ao sensível vai se confundir com o próprio reenvio entre essas qualidades, de maneira que a coisa apresentada não é nada à parte dos signos sensíveis que a apresentam e pode então doar-se em pessoa através deles.

O sentido de uma coisa habita essa coisa como a alma habita o corpo: ele não está atrás das aparências; o sentido do cinzeiro (pelo menos seu sentido total e individual, tal como ele se dá na percepção), não é uma certa ideia do cinzeiro que coordenaria seus aspectos sensoriais e que seria acessível somente ao entendimento; ele anima o cinzeiro, encarna-se nele com evidência. É por isso que dizemos que na percepção a coisa nos é dada "em pessoa" ou "em carne e osso" (Ibid., p. 369).

Entendamos: se graças ao reenvio mútuo entre qualidades sensíveis se desvela um sentido imanente aos perfis - o objeto intencional que os perfis apresentam -, o objeto não precisará ser apreendido por um ato da consciência que confira forma a uma matéria sensível opaca, passando desta ao plano da significação ideal, mas pode doar-se em pessoa nas mesmas qualidades sensíveis que o apresentam. Noutras palavras, o sentido e a unidade da coisa não se distinguem realmente das relações de implicação mútua nutridas pelas qualidades sensíveis, não havendo por isso exterioridade entre exprimido e expressão, coisa e manifestação.

Não é gratuita a ocorrência aqui do mesmo léxico com que 
Husserl comentava a relação entre multiplicidade noemática e objeto intencional. Porque, através da imanência entre coisa e significação, exprimido e expressão, o que se trata de explicar é a unificação do diverso sensível em torno de um mesmo objeto, sem contudo atribuir a esse "mesmo" qualquer exterioridade em relação ao múltiplo unificado. Vêm daí as passagens em que Merleau-Ponty, na linha de Husserl, afasta a ideia de uma coisa percebida que se situaria "atrás das aparências". Se apenas existe experiência de coisa segundo certa perspectiva, isto é, dentro de um determinado modo de doação, o "percebido ele mesmo" não poderá ser qualquer realidade neutra para além dos fenômenos; ele será o mesmo que as diferentes qualidades sensíveis apresentam por sua remissão mútua, uma "totalidade internoemática", nos termos de Gurwitsch, ou uma "aparência total", no termo equivalente de Merleau-Ponty. Como afirma a Fenomenologia, "a coisa é este gênero de ser no qual a definição completa de um atributo exige a definição do sujeito inteiro e em que, por conseguinte, o sentido não se distingue da aparência total" (Ibid., p. 373).

Mas esse conjunto de argumentos que garantem a imanência da coisa em suas aparências (sua doação evidente), da unidade na multiplicidade, é contrabalançado na Fenomenologia pela garantia inversa de que essa unidade, sem jamais se tornar uma realidade "atrás dos fenômenos", não é por isso menos irredutível em relação à multiplicidade. Assim, se as qualidades sensíveis anunciam umas às outras e, nessa remissão recíproca, anunciam a coisa, elas o fazem sem jamais a apresentar completamente; quer dizer, por mais que não haja aqui qualquer oposição "real" entre coisa e fenômeno, haverá sim uma oposição "intencional" entre o uno visado e o múltiplo dado, garantindo assim a trans- 
cendência intencional da coisa em relação à série de aparições. É que, em sentido fenomenológico, imanência e transcendência deixam de ser regiões exclusivas uma da outra, podendo-se então falar numa "transcendência na imanência", entendendo por isso a presença não-real porém evidente do termo visado. É esse o tipo de relação que sustenta, como mostrou o comentador, a compreensão da coisa percebida na Fenomenologia da percepção: anunciada em pessoa na remissão entre qualidades sensíveis nesse sentido, imanente a elas -, ela é aquilo de "mesmo" que se apresenta ali e, por isso, irredutível à multiplicidade que o apresenta - nesse sentido, intencionalmente transcendente em relação a ela (Moura, 2001, p. 255).

E essa relação de imanência e transcendência entre múltiplo e uno será ainda confirmada, na Fenomenologia, por meio da gramática das partes e do todo fornecida pela Gestalttheorie. Exorcizando a ideia de uma totalidade partes extra partes, a Gestalt indicava um Todo que, não tendo qualquer realidade para além daquela que deve às suas partes, será contudo irredutível a elas na medida em elas próprias são definidas não como positividades, mas exclusivamente como a função que desempenham no interior do Todo. Assim, por um lado, o Todo é irredutível às partes que o compõem, já que prescreve a função que as define, articulando as partes de maneira a formar esta totalidade e não outra: o Todo é anterior às partes; por outro, ele é também imanente a elas, já que não tem qualquer realidade senão a de ser uma determinada relação entre a partes, não sendo nada para além delas. A situação será a mesma na coisa percebida: ela é uma totalidade de perfis, eles próprios não positivos, que, sendo parte, reenviam imediatamente ao Todo do qual são parte, mas sem que se tenha, por definição, experiência direta desse Todo 
fora da parte que o apresenta.

A comparação entre a coisa percebida e a obra de arte ilustra perfeitamente bem essa "transcendência na imanência" que existe entre parte e todo, multiplicidade de aparições e unidade da coisa. Seja num quadro ou numa peça musical, o sentido da obra "só pode comunicar-se pelo desdobramento das cores e dos sons" (Merleau-Ponty, 2001a, p. 176), não existe "fora" dos signos que a exprimem, e, todavia, jamais coincide realmente com eles, sendo antes aquilo que eles significam. A transcendência do "sentido" é portanto indissociável de sua imanência com relação aos signos que o apresentam: na obra de arte, "não se pode distinguir a expressão do expresso", ela só pode "irradiar sua significação sem abandonar seu lugar temporal e espacial" (Ibid., p. 177). E o que vale para a obra de arte vale para a coisa percebida em geral: ela não se distingue "realmente" dos aspectos através dos quais ela se apresenta, mas tampouco se confunde com eles, sendo antes aquilo que é por eles apresentado e, nessa medida, os transcende. Que é o sentido de uma peça musical para além do conjunto sonoro? Certamente, nenhuma realidade a mais - mas, por outro lado, tampouco sua execução nota por nota.

Em qualquer caso, vê-se que essa fenomenologia não se está movendo no interior do realismo ingênuo da atitude natural, crítica que subjaz à censura de Gurwitsch à oposição real inexistente - entre objeto e manifestação na obra de MerleauPonty. "A relação dos aspectos perspectivos com a coisa que eles nos apresentam", já dizia A estrutura do comportamento, "não se reduz a nenhuma das que existem no interior da natureza" (Merleau-Ponty, 2001b, p. 293). Ao contrário, graças à noção de sentido perceptivo e à doutrina da expressão que a ampara, a 
unidade da coisa é imanente à sua multiplicidade, e não pode de modo algum ser pensada como uma realidade subsistente para além da série internoemática. Com isso, a coisa percebida vai sendo entendida como o núcleo convergente de uma série de aparições, uma "maneira única de existir" (Ibid., p. xiii) revelada a cada perspectiva sua, sem que haja uma visão "total" capaz de a apreender por inteiro. Em jargão: a coisa percebida se doa em pessoa através de seus aspectos ao mesmo tempo em que jamais se doa adequadamente. A primeira tese traduz a imanência do objeto em suas manifestações, sua doação evidente, o que depende da inexistência de oposição real entre ambos; a segunda, resultado do descompasso entre a síntese perceptiva finita e a inesgotabilidade de aspectos anunciados nos horizontes externo e interno da coisa, é a explicitação de como a Fenomenologia compreende sua transcendência. O "percebido enquanto tal" mostra-se transcendente em relação a suas manifestações, mas, graças ao fato de que ele não é senão a unidade presuntiva dessas manifestações, ele não é exterior a elas, nenhuma "transcendência real", podendo então nelas doar-se "em carne e osso". A situação aqui é no fundo ainda análoga àquela que ocorria em Husserl, quando este garantia, na Krisis, não apenas a correlação necessária entre cogitatio e cogitatum, mas também uma correlação entre a série de cogitata e o ente que através dela se apresenta. Viu-se, contudo, que esse estabelecimento era dependente da supressão do em-si. Merleau-Ponty não estaria então repetindo por sua conta esse mesmo passo de Husserl, recuperando a seu modo a doutrina do objeto intencional como $\mathrm{X}$ vazio de uma multiplicidade convergente de aparências? 


\section{IV}

Certos textos da Fenomenologia parecem rejeitar frontalmente essa identificação entre coisa percebida e "X vazio" husserliano. Numa passagem em que se trata de interpretar a "plenitude absoluta" da coisa percebida como sua densidade intersensorial, isto é, em que formula a tese segundo a qual o teor de realidade da coisa é diretamente proporcional à riqueza de experiências sensoriais às quais ela se oferece, Merleau-Ponty escreve:

a unidade da coisa para além de todas as suas propriedades fixas não é um substrato, um $\mathrm{X}$ vazio, um sujeito de inerência, mas esta entonação única que se reconhece em cada uma delas, essa maneira única de existir da qual elas são uma expressão secundária. Por exemplo, a fragilidade, a rigidez, a transparência e o som cristalino de um vidro traduzem sua maneira de ser única (Ibid., p. 368).

Noves fora a censurável assimilação do "X vazio" a uma espécie de "substrato" ou "sujeito de inerência" - o que é interpretá-lo como uma "realidade", atrasando em dois séculos a inovação da tese husserliana -, o texto sugere a interpretação da coisa percebida como uma "existência", uma "maneira única de existir" ou "estilo" singular da coisa. Mas essa "existência" poderia ser efetivamente uma unidade "para além" de seus modos de doação, uma espécie de "realidade" autônoma em relação à subjetividade? O argumento com o qual Merleau-Ponty formula a tese da "coisa em-si-para-nós" sugere o exato contrário. Pois o que está em questão ali é dar uma solução fenomenológica ao problema do realismo, quer dizer, trata-se de mostrar que o caráter "em-si" da coisa percebida é uma propriedade dos modos de aparição, e 
não a estipulação de uma "realidade autônoma" para além deles. Para Merleau-Ponty, o que me sugere a "aseidade" da coisa percebida - persuadindo-me de que ela não depende de meus atos exploratórios para ser o que é - não é nada senão o descompasso entre a infinidade de aspectos conforme os quais ela se apresenta (já que cada aspecto seu reenvia indefinidamente a outros) e a finitude da exploração perceptiva, cujo decurso temporal impede de se concluir a exploração com uma síntese completa. Numa palavra, a "aseidade" da coisa percebida (sua transcendência) não é senão a inadequação essencial de seu modo de doação ${ }^{1}$. Assim, é paradoxalmente uma experiência subjetiva que atesta o "em-si" das coisas, e isso muito antes que a idealização traduza, por uma passagem ao limite, essa "plenitude perceptiva" numa "plenitude da objetividade" (Merleau-Ponty, 2001b, p. 255). De maneira coerente, a doutrina do "em-si-para-nós" acarreta um conceito original de "realidade", formulado em consonância com o a priori da correlação: ela não indica uma subsistência do em-si para além do fenômeno, mas sua densidade interna, isto é, o sistema mesmo de reenvios entre sentidos ou aspectos que, longe de remeterem a outra coisa da qual seriam representantes extrínsecos, confundem-se com sua "aparência total".

Descobrimos agora o núcleo da realidade: uma coisa é coisa porque, o que quer que nos diga, ela o diz pela própria organização de seus aspectos sensíveis. $\mathrm{O}$ "real" é este meio em que cada coisa é não apenas inseparável das outras, mas de alguma maneira sinônima

1"A crença na coisa e no mundo só pode significar a presunção de uma síntese acabada, e todavia este acabamento é tornado impossível pela própria natureza das coisas a ligar, já que cada uma delas reenvia indefinidamente, por seus horizontes, a outras perspectivas" (Merleau-Ponty, 2001a, p. 381). 
das outras, em que os "aspectos" se significam uns aos outros em uma equivalência absoluta; ele é a plenitude intransponível: impossível descrever completamente a cor do tapete sem dizer que ela é cor de um certo valor tátil, um certo peso, uma certa resistência ao som (Ibid., p. 373).

Mas, então, se o conceito de "realidade" é reinterpretado fenomenologicamente como certa característica própria ao modo de doação da coisa - portanto, respeitando-se perfeitamente sua correlação com uma subjetividade -, se a miragem de uma "realidade em-si" exterior à manifestação encontra-se dissolvida, e se, por outro lado, continua-se a apresentar o objeto como transcendente em relação aos fenômenos, como evitar a interpretação husserliana do objeto intencional como o $\mathrm{X}$ vazio (nenhuma realidade per se) de uma multiplicidade de aparições? Aparentemente, isso equivaleria a aceitar todas as premissas do raciocínio e recusar-lhe, já tarde demais, a consequência impositiva. Porém, nesse caso, como entender o agravo textualmente existente de Merleau-Ponty à compreensão do objeto como X idêntico?

É verdade que o texto em que Merleau-Ponty formula explicitamente essa crítica tem por alvo, sobretudo, o objeto transcendental kantiano. Mas ela não deixa de ricochetear em Husserl, pelo menos quando Merleau-Ponty, em substituição ao "X vazio", for entender aquele polo transcendente como uma "existência" concreta ou "maneira única de existir". Tudo se passa como se Merleau-Ponty pretendesse aplicar à coisa percebida "existente" o modelo husserliano da constituição intencional do objeto através de seus noemata, contrabandeando dessa forma para o domínio mundano da percepção real as propriedades fenomenológicas descobertas em domínio originalmente transcendental. A corre- 
lação perceptiva e a relação interna entre o aparecente e o aparecer estariam mantidos, porém transpostos ao ambiente concreto da coisa material faticamente existente ${ }^{2}$. Mas, se isso é verdade, Merleau-Ponty estaria subrepticiamente identificando, como já se sugeriu, "objeto intencional" (irrealidade) e "objeto puro e simples" considerado como "realidade material autônoma", impondo a gramática fenomenológica da doação aos domínios da atitude natural nos quais Husserl jamais sonhara em intervir (Ferraz, 2009, p. 192). Sabe-se que Husserl jamais entenderia o objeto intencional como uma existência, e a redução fenomenológica já era suficiente para prever esse resultado. Era por isso que, ao distinguir entre a percepção de uma árvore real que queima (o objeto puro e simples) e o "sentido" dessa percepção (o objeto qua intencional) que não pode queimar, Husserl limitava ao segundo a validade das análises fenomenológicas, abstendose de qualquer consideração acerca dos objetos da natureza e da facticidade em geral (Husserl, 1976, p. 205). Sem realizar a epoché radical, Merleau-Ponty estaria condenado a confundir

\footnotetext{
${ }^{2}$ Nessa hipótese, que é a de alguns comentadores, restaria justamente o problema de dar uma solução convincente para o modo de ser dos perfis: já que no domínio dos "objetos puros e simples" não há lugar para o "fenômeno em sentido ôntico", as Abschattungen, cabe perguntar se os perfis serão doravante fenômenos realmente subjetivos, habitantes internos da cogitatio, ou então propriedades reais do objeto transcendente. Não se vê outra alternativa. Ao tomar a percepção como evento real ligando um vivido e um objeto realmente transcendente, Merleau-Ponty regrediria à decodificação brentaniana da oposição entre imanência e transcendência, tornando ao menos enigmático o estatuto do perfil da coisa percebida, isto é, do noema. $\mathrm{Na}$ verdade, o problema é rigorosamente simultâneo: a interpretação do modo de ser do objeto como transcendência real decide imediatamente uma interpretação do modo de ser das Abschattungen, que parece ficar sem alternativa senão compreender o perfil como uma qualidade objetiva da coisa ou como sensação puramente subjetiva.
} 
obstinadamente essas duas acepções de "ser-objeto"?

Não é bem assim. Vimos que a censura merleau-pontiana à presunção de redução completa não implicava uma inversão $d u$ pour au contre, e sem dúvida não era suficiente para encerrar a Fenomenologia no mesmo domínio das disciplinas de atitude natural, haja vista aliás a constante crítica ali endereçada às variadas formas de objetivismo. Da mesma forma, e como a tese da redução incompleta não equivale à tese de uma redução inexistente, a censura de Merleau-Ponty à concepção husserliana do objeto intencional não deságua por si só na concepção do objeto como realidade material independente da subjetividade. Antes do que recuperar alguma validade intrínseca para a atitude natural, com a noção de objeto puro e simples que ela veicula, trata-se de constatar que, entre ela e seu contrário transcendental, existe um terceiro domínio, irredutível aos dois anteriores, que Husserl na Krisis já descrevia como o Lebenswelt e que a Fenomenologia batizará de campo fenomenal. É nesse terceiro domínio que a filosofia merleau-pontiana pretende explicitamente encontrar seu território próprio de exploração, e por isso não existe uma confusão entre o objeto qua intencional e o objeto puro e simples, mas a circunscrição de um território da fenomenalidade que se distingue tanto da imanência transcendental de Ideias $I$ quanto da natureza objetiva da atitude natural.

\section{V}

O campo fenomenal merleau-pontiano recobre, ao menos em parte, o lugar atribuído por Husserl ao Lebenswelt como tema das ciências do espírito na Krisis. Nele, a subjetividade aparece como um ego pessoal pertencente a uma comunidade in- 
tersubjetiva e a um mundo humano, histórica e culturalmente particularizado, nutrindo com seu meio ambiente relações de motivação. É isso o que, num primeiro momento, começa a afastar o mundo-da-vida do território estritamente fenomenológicotranscendental de Ideias $I$ : enquanto neste o sentido do mundo é assimetricamente constituído pela consciência, ela própria desimplicada do mundo, no mundo-da-vida da atitude personalista existem predicados antropológicos capazes de motivar o comportamento do sujeito. As relações intencionais que se desdobram aqui entre o ego pessoal e seu meio circundante são, como diz Husserl, relações de "raios dúplices": os raios vão do centro da consciência em direção aos objetos, constituindo-os, eles "depois fazem o caminho inverso, dos objetos em direção ao centro, em múltiplos cruzamentos de suas propriedades fenomenológicas" (Husserl, 1952, p. 105). Desde então, o sujeito não é mais desimplicado do mundo, unilateralmente constituinte de seu sentido, como ocorre na orientação teórica e estritamente transcendental de Ideias I, encontrando-se antes motivado por este e, por isso mesmo, preso à mesma trama intencional que deveria constituir. Existe assim, nos limites dessa correlação mundana, um vai-e-vem entre constituinte e constituído, circularidade que Merleau-Ponty comentará amplamente na Fenomenologia como aquela própria à transcendência do ser-no-mundo.

Por outro lado, a mesma noção de motivação permite distinguir o mundo-da-vida da natureza objetiva comentada pela atitude naturalista: se nesta apenas vicejam relações de causalidade entre a coisa e a psyché, ambos entendidos como partes reais de uma natureza partes extra partes, a motivação aponta, ao contrário, para relações em que o "antecedente só age por seu sentido" (Merleau-Ponty, 2001a, p. 299). Um rápido contraste 
entre a natureza objetiva e o mundo vivido permite reconhecer três aspectos que singularizam este último: primeiro, se a natureza objetiva é tomada pelas ciências como uma realidade em-si, independente de seu modo subjetivo de doação, o Lebenswelt é essencialmente subjetivo-relativo, dependente de um comportamento valorativo do eu pessoal; segundo, se na primeira as relações são sempre reais, no segundo elas são motivadas por predicados de sentido; terceiro, se a natureza objetiva é considerada como de direito determinável geometricamente - herança da matematização galileana da natureza, como mostra Husserl no $§ 9$ da Krisis -, no segundo as formas percebidas são dadas de maneira apenas aproximativa, o que faz da inexatidão uma propriedade eidética do modo de doação do percebido. É assim o prejuízo do mundo e o ideal da determinação completa que marcam o mundo objetivo das ciências e o afastam, como idealização secundária historicamente produzida, do mundo originariamente percebido. Que se lembre a célebre descrição da ilusão de Müller-Lyer: se as retas ali não são nem iguais nem desiguais, se é apenas "no mundo objetivo que essa alternativa se impõe", é preciso reconhecer que existe um nível original da experiência em que "as noções contraditórias se entrecruzam porque os objetos não estão postos no terreno do ser" (Ibid., p. 12). Se o mundo objetivo é aquele em que opera o prejuízo do serdeterminado, no campo fenomenal essa exigência lógica não tem validade. Dessa forma, se a indeterminação positiva do percebido deve ganhar algum direito de cidadania, isso se dá num campo fenomenal anterior à objetividade, no qual o princípio do terceiro excluído, válido no terreno das ciências, é posto fora de circuito.

Entretanto, a relatividade ao sujeito, as relações de motivação 
e o reconhecimento do indeterminado positivo como modo de doação essencial ao percebido não bastam para circunscrever inteiramente a diferença do campo fenomenal em relação à objetividade. Mais fundamentalmente, a originalidade do mundo percebido reside no seu caráter de estrutura de horizonte, que é o que melhor circunscreve o território fenomenal merleau-pontiano em oposição tanto à natureza objetiva quanto a seu homônimo estritamente transcendental. É em primeiro lugar a própria ideia de mundo que inexiste na atitude naturalista das ciências: "a noção de um universo, isto é, a de uma totalidade acabada, explícita, na qual as relações são de determinação recíproca, excede aquela de um mundo, isto é, a de uma multiplicidade aberta e indefinida na qual as relações são de implicação recíproca" (Ibid., p. 99). Ou seja, enquanto o universo das ciências é partes extra partes, no campo fenomenal existe uma estrutura de remissões $a$ priori entre dados atuais e dados potencialmente visados, e que condiciona a própria aparição de coisa singular. É essa relação de implicação mútua entre as coisas percebidas, no horizonte externo, e entre os perfis de cada coisa, no horizonte interno, que simplesmente inexiste na compreensão objetivista da natureza. Ora, reside aqui a chave para se entender a alternativa que o mundo fenomenal representa tanto em relação ao realismo da atitude natural, no qual o universo surge como agregado de positividades independente da consciência, quanto ao idealismo da constituição transcendental, no qual o mundo aparece como correlativo de uma consciência absolutamente prestadora. Se, contra o primeiro, a ideia de horizonte supõe a relatividade a uma subjetividade, contra o segundo, as remissões autóctones descobertas na intencionalidade de horizonte dispensam a Auffassung da consciência ativa e, por isso, têm por correlato uma subje- 
tividade passiva que apenas assiste ao desdobrar-se autóctone daqueles reenvios. Mas, então, não digamos mais que MerleauPonty teria imposto a gramática fenomenológica da doação ao domínio da atitude natural espontaneamente realista, confundindo objeto qua intencional e objeto puro e simples - o que significaria avançar sobre um domínio no qual o fenomenólogo precavido jamais deveria ter pensado em intervir. Digamos, ao contrário, que o campo fenomenal indica um território original, aquém da objetividade, caracterizado pela ideia de mundo como estrutura de horizonte e pelo a priori correlacional estabelecido não entre uma consciência ativa e um mundo inteiramente constituído, mas entre uma subjetividade passiva e as remissões internoemáticas autóctones do mundo percebido. Como será na temporalidade que essa intencionalidade de horizonte terá seu fundamento, é ela que assegurará em fim de contas a originalidade do campo fenomenal em relação tanto ao universo partes extra partes do naturalismo quanto ao mundo de significações inteiramente constituído de Ideias $I^{3}$.

Sendo assim, a obtenção desse campo fenomenal exige a efetuação de uma redução fenomenológica precisa, da qual a epoché do prejuízo do mundo e do ideal da determinação completa fornece apenas uma visão parcial. Se a delimitação última da legalidade desse campo será encontrada na temporalidade, que é no fundo a raiz da indeterminação do percebido tal como con-

\footnotetext{
${ }^{3}$ Evidentemente, essa fundação da intencionalidade de horizonte sobre as sínteses temporais tem por pressuposto a tese, explicitamente afiançada pela Fenomenologia, mas implicitamente rejeitada pelos textos posteriores de Merleau-Ponty, da anterioridade do sentido interno sobre o sentido externo. Por razões às quais aludiremos no final deste artigo, é a anterioridade do tempo sobre o espaço que começa a ser revisada nos escritos merleaupontianos dos anos 50 - contra, bem entendido, o livro de 1945.
} 
cebida em 1945, ocorre aqui aquilo que J.-F. Lavigne chamou, a propósito do $§ 1$ das Lições sobre a consciência interna do tempo, de uma "radicalização da redução" - que não se confunde, bem entendido, com a "segunda redução" da Krisis ou de Ideias I por meio da posição entre parênteses do tempo objetivo e das coisas que se movem nesse estrato da objetivação ${ }^{4}$. Com isso, é precisamente a descoberta de uma intencionalidade operando já no nível da sensibilidade o que a fenomenologia descobre. Em seu escoar temporal, a sensação - tema de uma explícita reabilitação, tão anti-empirista quanto anti-intelectualista, por parte de Merleau-Ponty - torna-se um componente do vivido cujas fases de duração são as multiplicidades últimas de cuja síntese (passiva) surgirá a unidade hylética capaz de acoplar-se, na apreensão noética, a uma forma intencional constituinte de objeto. É o tempo, dessa maneira, que está na raiz da unificação passiva da sensação, e, como esta serve de base para as constituições superiores, da coisa percebida em geral. Desse ponto de vista, ele indica com precisão a anterioridade constituinte do fenomenal em relação à coisa situada no primeiro grau da objetivação de que Husserl falava no §34 das Lições de 1905. ${ }^{5}$ Pondo esse

\footnotetext{
4،... aplicada ao vivido perceptivo, a consideração não-empírica de seu conteúdo real faz surgir com evidência a eclosão do objeto unitário em uma multiplicidade de data sensíveis (hyléticos), dispersos ao longo da sucessão temporal: é portanto a temporalidade, e sua eventual função sintética, que detém o princípio primeiro da possibilidade de um objeto em geral" (Lavigne, in: Husserl, 1989, p. 13).

${ }^{5}$ Husserl apresenta do seguinte modo as três camadas da objetivação: "1) As coisas da experiência no tempo objetivo (no qual seria preciso distinguir ainda diversas camadas do ser empírico, que não foram até aqui levados em conta: a coisa da experiência do sujeito isolado, a coisa intersubjetivamente idêntica, a coisa da física); 2) As multiplicidades de aparições constituintes, de camada diferente, as unidades imanentes no tempo pré-empírico; 3) O fluxo absoluto da consciência, constituinte do tempo" (Husserl, 1966, p. 73).
} 
primeiro estrato fora de circuito, é evidente o que acontece com a coisa percebida na Fenomenologia: ela se torna uma coisa temporal, um Zeitobjekt de segunda camada.

\section{VI}

Tanto o X vazio husserliano quanto o objeto puro e simples são afastados em benefício de uma temporalização da coisa percebida cuja validade é circunscrita ao campo fenomenal, no qual o "prejuízo do ser-determinado", por um lado, e o "tempo cósmico" da terceira camada da objetivação por outro, encontramse postos em suspenso. Assim, a "maneira única de existir" de que falava a Fenomenologia aponta para uma compreensão da coisa percebida como não existindo fora de seus perfis sensíveis, com sendo o "mesmo" que eles apresentam, mas que está ademais constantemente se produzindo e se modificando através deles, como uma identidade incapaz de ser possuída anteriormente à exploração perceptiva. Essa última característica é o que deve afastar a compreensão do objeto intencional como um $\mathrm{X}$ vazio da ordem da idealidade. Pois o modelo perfeito desse "estilo único" da coisa temporalmente percebida - o "mesmo" que se apresenta nas apresentações e que se faz através delas, como uma "unidade em curso" - é a melodia sonora, cuja identidade jamais se desgarra da diferença através da qual se constitui:

A significação musical da sonata é inseparável dos sons que a carregam: antes que a tenhamos escutado, nenhuma análise permite adivinhá-la; uma vez terminada a execução, não poderemos mais, em nossas análises intelectuais da música, reportar-nos ao momento da experiência; durante a execução, os sons não são 
apenas os "signos" da sonata, mas ela está presente através deles, ela desce neles (Merleau-Ponty, 2001a, p. 213).

Sem se confundir com nenhuma das notas tomadas isoladamente, a unidade melódica, ao mesmo tempo em que é produzida pelo conjunto de notas, é o que prescreve a cada uma delas sua tonalidade e sua função, de modo que, se é impensável uma significação musical destacada dos sons, é igualmente impensável um som que não seja imantado por uma significação transcendente - transcendência que, evidentemente, não é nenhuma "transcendência real". Assim, se não há o idêntico da melodia fora das notas, pois a melodia depende de ser apresentada por sons efetivos, por outro lado, ela tampouco se confunde com a mera soma das próprias notas: enquanto se escuta as notas uma por uma, tem-se consciência de uma melodia, isto é, tem-se consciência da diferença entre melodia transcendente e a variedade de notas que a apresentam. E como o momento do idêntico na melodia está em contínua mudança através do diverso sonoro, essa diferença não se deixa hipostasiar, dando origem à miragem de uma significação para além das notas efetivas. É dizer que a identidade melódica não apenas inexiste fora de seus casos, mas está além disso em contínua modificação através deles, apresentando-se como uma "unidade em curso". Noutras palavras, a presunção de objetivação de um "mesmo" que se apresentaria ao longo de seus múltiplos perfis é impossível desde que se considere o caráter intrinsecamente temporal desse perfilhamento. Se ao perceber uma série de perspectivas de um objeto estaticamente considerado, sob diversos ângulos e distâncias visuais, posso em determinado momento acreditar estar de posse do eidos desse objeto e passar a ver então, em cada 
um de seus modos de doação, diferentes atualizações empíricas daquela mesma essência ideal, essa presunção de objetivação do invariante já não pode ocorrer na melodia e na coisa temporal em geral, pois nela o momento da identidade não pode ser apartado do fluxo que o constitui, diferença e identidade passando continuamente uma na outra, como mostrou muito bem Gérard Granel:

o movimento de uma frase musical (...) é o que melhor corresponde à noção de Zeitobjekte. Ela não comporta, com efeito, a fixação objetiva do momento da unidade ou momento do "mesmo", como a casa ou a mesa cuja identidade recobre e mascara a temporalidade. Há na música, por assim dizer, empate entre o mesmo e o outro (...). Nela, o momento da identidade não deixa de ser levado pelas ondas de sua constituição, ao mesmo tempo em que o fluxo não deixa de desdobrar a identidade. A melodia é a paz dos opostos metafísicos, a matéria que permanece na forma e a forma que permanece na matéria (Granel, 1968, p. 57).

Essa observação permite entrever o pano de fundo em que se formulava a objeção merleau-pontiana ao objeto intencional como idealidade. Era a revalorização filosófica da percepção, isto é, a descoberta de um sentindo autóctone e de uma forma intencional sugerindo-se espontaneamente na matéria sensível, que conduzia naturalmente a essa crítica. Pois a partir de que momento se impusera a unificação ideal da diversidade de aspectos? Entenda-se por "ideal" aqui aquilo que tanto MerleauPonty quanto o Husserl de Experiência e juízo entendiam por esse termo, a saber, a unidade sintética de nível predicativo. 
Era devido à descontinuidade do sensível, pensa Merleau-Ponty, interpretado de antemão como aglomerado de partes discretas, que, sem poder se apoiar em uma pré-unificação já realizada espontaneamente na sensibilidade, a síntese da diversidade de seus aspectos devia ser reportada diretamente ao juízo. E então não era de se espantar que a unidade assim obtida fosse uma forma destacada da hylé, um invariante da ordem da idealidade - precisamente como o intelectualismo compreendia o objeto intencional. Era contra isso que, abaixo e como condição dessa "significação intelectual", a Fenomenologia procurava descobrir uma "unidade antepredicativa do mundo percebido" (MerleauPonty, 2001a, p. 272), ela própria produzida pela expressividade imanente ao sensível, entendamos, pelo sistema de reenvios recíprocos entre aspectos sensíveis que dispensaria, portanto, uma unificação via síntese predicativa e, mais amplamente, todo o dualismo entre matéria e forma envolvido na intencionalidade de ato. Vem daí o elogio merleau-pontiano à síntese de transição como unificação imanente das perspectivas da coisa percebida, antes que a atividade explícita do juízo entre em cena: "Não tenho uma visão perspectiva, depois outra, e entre elas uma ligação de entendimento, mas cada perspectiva passa na outra, e, se podemos ainda falar de síntese, trata-se de uma "síntese de transição" (Ibid., p. 380). Se uma perspectiva pode "passar na" outra, é que ela não é nenhuma positividade em si, ela se qualifica e se determina exclusivamente no reenvio recíproco às demais perspectivas, assim como a nota atualmente escutada não indica uma fase discreta da unidade melódica.

Mas o que assegura a expressividade entre as partes do percebido, seu reenvio mútuo, com que o mundo sensível passa a ser caracterizado? Na Fenomenologia - diferentemente do que ocor- 
rerá a partir dos anos 50, quando é a diacriticidade do mundo sensível que garante a não-positividade e a remissão recíproca das partes -, Merleau-Ponty permanece nesse ponto um fiel discípulo de Husserl e se limitará a descobrir, com ele, nas sínteses passivas realizadas pela temporalidade o núcleo onde se forma a unificação imanente do diverso sensível. Pois, de um lado, se cada perspectiva do percebido não é nenhuma positividade, isso se dá da mesma maneira pela qual, no fluxo do tempo, o instante impressional no qual a fase atual do objeto é apresentada sempre-já se tornou passado, escoando para o fundo da retenção. Mas também porque, de outro lado, o fluxo é acompanhado de uma intencionalidade original - a retenção - que se encarrega de conservar, a cada nova fase atual do objeto, a quase-presença das suas fases recém-passadas. Assim, o escoamento pelo qual o instante atual se torna passado não implica qualquer descontinuidade temporal; pelo contrário, ele se identifica em verdade ao perfilhamento originário daquele mesmo "agora" que, ao mover-se em direção ao "passado", ganha correlativamente novos "modos de ser dado" para os sucessivos e sempre novos - graças ao escoamento do tempo - focos atuais da impressão.

Com essa referência à constituição do Zeitobjekt através de suas fases temporais, avançamos na compreensão da "unidade em curso" que Merleau-Ponty encontrava na melodia e, no fundo, na percepção em geral? Procurava-se uma unidade que não subsumisse idealmente o diverso, mas que ao contrário se gestasse na multiplicidade fática mesmo restando transcendente a ela. Com a síntese temporal, descobriu-se que a fase atual do objeto não soçobra quando passo do agora impressional ao passado; ela permanece retida, iniciando a série de adumbramentos do 
mesmo objeto, que só se interrompe quando o fluxo também se interromper. Assim, o objeto está em constante constituição através do tempo, ele se enriquece com a persistência da exploração temporal - a passagem para o futuro do foco da impressão é ipso facto o aumento da série retencional na qual o objeto se perfila -, e é justamente por isso que ele não é uma idealidade, não salta para fora da diversidade de fases que o alimentam.

O tempo esclarece, dessa maneira, as características da fenomenização com que Merleau-Ponty pensa o objeto intencional. Por um lado, ele está presente em pessoa nos seus perfis: a fase "retida" não é uma fase "rememorada", não preciso passar por um ato explícito do perfil ao "original", pois o que é dado é o próprio objeto "visto por transparência" através de sua perspectiva, "da mesma maneira como vejo o próprio pedregulho através das massas de água que deslizam sobre ele" (Ibid., p. 478). É, assim, o próprio objeto que está quase-presente no campo perceptivo através da retenção (e mutadis mutandis através da protensão). Por outro lado, esse objeto nunca se apresentará adequadamente, isto é, de maneira completa: seria supor o acabamento do tempo, uma síntese que pudesse se erguer por cima do fluxo temporal, deixando de ser ela própria um ato, um vivido que se desdobra no tempo. Se é assim, o objeto está continuamente se constituindo através dos múltiplos perfis que o oferecem, o que é dizer que a exploração perceptiva, desdobrando-se no tempo, nunca possuirá o objeto de modo completamente determinado - na exploração, são novos perfis e determinações desse mesmo objeto-tema que vou paulatinamente descobrindo, mas, porque não há síntese que reúna a totalidade do tempo (ela é sempre um ato finito da consciência temporal), esse objeto está situado no infinito, imantando à distância a exploração perceptiva tal 
como a Ideia kantiana.

É esse, no fim das contas, o destino do objeto intencional ao ser aclimatado na filosofia da existência peculiar à Fenomenologia da percepção: ele se torna um Zeitobjekt, cuja doação completa se situa presuntivamente no infinito. E assim, a experiência perceptiva está assegurada por uma dupla certeza: sei estar explicitando progressivamente o mesmo objeto percebido ao acompanhar seus aspectos, mas sei também que essa explicitação jamais será completa, razão pela qual essa Ideia reguladora em que se converteu a objetividade será também sempre, de fato, aproximativa, de contornos fluidos, o que não é senão o que Merleau-Ponty chamava, na Fenomenologia, de "indeterminação do percebido". Donde a concepção final da transcendência do objeto percebido na Fenomenologia. Sem dúvida, ele será um "indeterminado", mas, como essa indeterminação não é senão o avesso da finitude da exploração perceptiva, a sua doação completa, proibida "de fato", não deixa de ser autorizada "de direito", permanecendo como Ideia reguladora, situada no infinito de horizonte e imantando os diversos aspectos que percorro paulatinamente na percepção.

Essa postulação da identidade do objeto como situada no infinito seria arbitrária? De modo algum. Ela é necessária para dar conta do fato de que, na exploração perceptiva da coisa, tenho a experiência de que seus perfis se recobrem em torno de um mesmo tema. Se o "tipo" do objeto percebido não for de antemão vislumbrado por mim como aquilo de que os perfis são perfis, simplesmente o curso temporal de experiências se desagregaria num vir-a-ser indiferente de aparências. Consequentemente, sem essa antecipação do estilo constante do objeto, não haveria nem a consciência de perfil enquanto perfil - já que este 
não apresentaria nada distinto de si mesmo -, nem a experiência de qualquer continuidade perceptiva, nenhuma ligação interna entre as fases atuais e inatuais da percepção; o mundo se estilhaçaria em um caos perceptivo. E, sendo assim, nem haveria a experiência de se perceber cada vez melhor ou pior um mesmo objeto; a série de perfis tornar-se-ia desregrada e sem possibilidade de aferir distintos graus de preenchimento. Eis porque a identidade do objeto deve ser vislumbrada em horizonte no curso da exploração perceptiva, como condição para que essa exploração diga respeito a um mesmo aparecente: "o horizonte é então aquilo que assegura a identidade do objeto no decorrer da exploração, é o correlativo da potência próxima que meu olhar conserva sobre os objetos que acaba de percorrer e que já tem sobre os novos detalhes que vai descobrir" (Merleau-Ponty, 2001a, p. 96). Mas, se é assim, pode-se efetivamente sustentar que essa unidade do objeto apenas se forme ao longo da série concordante ou discordante de aparições que se dão no tempo? Ao contrário, ela parece estar de antemão pressuposta, como tipo fluido do objeto, necessária justamente para que a série de aparições possa ser mais do que um vir-a-ser indiferente de aparências, e cujo grau máximo de adequação se encontra apenas no infinito.

Isso aponta para os limites da concepção de transcendência presente na Fenomenologia: ao temporalizar o $\mathrm{X}$ vazio husserliano, Merleau-Ponty faz dele um "tipo" de contornos fluidos como o sentido de uma frase musical, essa unidade melódica en se faisant e contudo pressentida como quase-presente em cada nota particular -, mas cuja indeterminação de fato não é senão promessa de determinações possíveis, presunção - situada no infinito - da doação completa da coisa. Não é reconhecer que 
a presunção da doação adequada - uma das figuras do prejuízo mais geral do objetivismo husserliano, como mostrou Barbaras (Barbaras, 1998) -, longe de ser extirpada, permanece cativa da temporalização do objeto percebido realizada na obra de 1945? Não é casual que a fenomenologia husserliana da temporalidade, fundamento último da coerência das descrições da Fenomenologia da percepção, vá praticamente desaparecer nos escritos subsequentes de Merleau-Ponty. Através disso, é um outro conceito de transcendência que começará a ser gestado, precisamente contra a presunção de uma doação adequada da coisa, mesmo que situada no infinito como Ideia kantiana - como o faz a Fenomenologia -, o que é ainda no fundo uma maneira de pensar, sorrateiramente, a transcendência da coisa percebida em analogia com aquela de um objeto completamente determinado, apenas introduzindo, para distinguir a primeira delas, a finitude da subjetividade temporal, e encetando assim uma compreensão apenas ôntica da transcendência do percebido.

\section{Referências bibliográficas}

BARBARAS, R. "Merleau-Ponty et la racine de l'objectivisme husserlien". In: Le tournant de l'expérience. Paris: Vrin, 1998. FERRAZ, M. S. Fenomenologia e ontologia em Merleau-Ponty. Campinas: Papirus, 2009.

GRANEL, G. Le sens du temps et de la perception chez Husserl. Paris: Gallimard, 1968.

GURWITSCH, A. Théorie du champ de la conscience. Bruges: De Brouwer, 1957.

HUSSERL, E. Die Krisis der europäischen Wissenschaften und die transzendentalen Phänomenologie. Haag: Martinus Nijhoff, 1976; tradução francesa G. Granel. Paris: Gallimard, 2004. 
___. Ideen zu einer reinen Phänomenologie und phänomenologischen Philosophie (Erstes Buch). Haag: Martinus Nijhoff, 1976; tradução brasileira M. Suzuki, São Paulo: Ideias e Letras, 2006.

. Ideen zu einer reinen Phänomenologie und phänomenologischen Philosophie (Zweites Buch). Haag: Martinus Nijhoff, 1952; tradução brasileira M. Suzuki, São Paulo: Ideias e Letras, 2006.

. Zur Phänomenologie des inneren Zeitbewusstseins. Haag: Martinus Nijhoff, 1966.

LAVIGNE, J.-F. "Introduction" In: HUSSERL, E. Chose et espace. Leçons de 190\%. Paris: PUF, 1989.

MERLEAU-PONTY, M. Phénoménologie de la perception. Paris: Gallimard, 2001a. ___. Structure du comportement. Paris: PUF, 2001b.

MOURA, C. A. R. "A cera e o abelhudo". In: Racionalidade e crise. São Paulo: Discurso/UFPR, 2001.

Crítica da razão na fenomenologia. São Paulo: Edusp/Nova Stella, 1989. 
